\title{
Time - Course of Sodium Arsenate Induced Hepatotoxicity and Nephrotoxicity in Male Wistar Rats
}

\author{
John O. Fatoki ${ }^{*}$, Gbadebo E. Adeleke ${ }^{1}$, Jelili A. Badmus ${ }^{1}$, Olusegun K. Afolabi ${ }^{1}$, Olaniyi T. Adedosu ${ }^{1}$, \\ Samuel A. Kehinde ${ }^{2}$, Adeniran S. Adekunle ${ }^{1}$
}

1. Department of Biochemistry, Faculty of Basic Medical Sciences, College of Health Sciences, Ladoke Akintola University of Technology, P.M.B 4000, Ogbomosho, Nigeria

2. Department of Biochemistry, College of Biosciences, Federal University of Agriculture, Abeokuta

* E-mail of the corresponding author: jofatoki@lautech.edu.ng

(Dr. John O. Fatoki. Department of Biochemistry, Faculty of Basic Medical Sciences, College of Health Sciences, Ladoke Akintola University of Technology, P.M.B 4000, Ogbomosho, Nigeria).

\begin{abstract}
Arsenic exposure has been implicated by several epidemiological studies as an important metalloid that is currently poisoning millions of people globally. In order to investigate the time - course of arsenic exposure on hepatic and renal toxicity, male albino rats $(n=45)$ were exposed to arsenic ( $100 \mathrm{ppm}, 150 \mathrm{ppm}$ and $200 \mathrm{ppm})$ for 4,8 and 12 weeks as sodium arsenate in their drinking water. Control animals $(n=15)$ received distilled water for the same period after which blood and vital organs were removed from the animals and analyzed for alanine amino transaminase (ALT), aspartate amino transaminase (AST) gamma amino transaminase $(\gamma \mathrm{GT})$, alkaline phosphatase (ALP), creatinine and urea spectrophotometrically. Histological changes in hepatocytes was also examined. Before the commencement of arsenic exposure, five animals were sacrificed to obtain baseline data. Significant elevation in plasma ALT, AST, $\gamma \mathrm{GT}$ and alkaline phosphatase activities characterized the effect of the arsenical at all doses and time interval relative to the controls. Plasma levels of creatinine and urea were also elevated at all-time intervals in the arsenic group. In most of the cases observed, the elevated level of these biochemical marker in circulation are time - and dose - dose dependent. Hepatic histopathology reveals degeneration of cytoplasmic contents, evidence of necrosis, collapse of central vein, cytoplasmic inclusion and enlarged hepatic sinusoids in arsenic - exposed groups. These findings suggest that different dose regimens of sodium arsenate at different time interval caused degenerative changes in hepatic and renal tissues in rats in dose - and time - dependent fashion.
\end{abstract}

Keywords: Arsenic, Time - course, Hepatotoxicity, Nephrotoxicity

DOI: $10.7176 / \mathrm{JNSR} / 9-4-09$

\section{Introduction}

Increasing human activities have led to the contamination of air, water, soil and food especially with the toxic, non-essential elements such as arsenic (As), mercury (Hg), cadmium (Cd) and lead (Pb) (Clarkson, 1995). Among these metals, arsenic, a ubiquitous metalloid, exhibits a complex metabolism and is possibly the most abundant pollutant (Hu, 2000; Pradosh \& Anupama, 2000). In fact it is ranked first in a list of 20 hazardous substances by the Agency for Toxic Substances and Diseases Registry and United States Environmental Protection Agency (Goering, 1999).Arsenic, either as trivalent arsenite (AsIII) or pentavalent arsenate (AsV), is a naturally occurring common environmental toxicant that is widely distributed in the biosphere (Chowdhury et al., 2000; Haider \& Najar, 2008). It is an epidemiologically important metalloids that is currently poisoning tens of millions of people worldwide (Hughes et al., 2011; Smeester et al., 2011).

Arsenate is released from several anthropogenic sources such as mining wastes, mineral debris, glass manufacture, computer chips, wood preservatives, insecticides, and some agrochemicals (Rordriguezet et al., 2003), making it a global underground water contaminant (Guillamet et al., 2004; Odunola et al., 2008; Gbadegesin et al., 2009). In humans and some experimental animals, the inorganic form of arsenic has been established to be a potential carcinogen. The inorganic arsenic is methylated to monomethylarsonic acid (MMA) and finally to dimethylarsenic acid (DMA) and this metabolism is followed by urinal excretion. This arsenic biotransformation has been previously proven to lead to DNA hypomethylation arising from continuous depletion of methyl group resulting into aberration in gene expression, which in turn causes abnormality in cell proliferation that eventually results in carcinogenesis (Pradosh \& Anupama, 2002).

Previous studies have reported various arsenic-induced catastrophes (Hughes \& Najar, 2011; Mazumber \& Dasgupta, 2011), which include, but not limited to hypertension, diabetes mellitus, atherosclerosis, impaired 
microcirculation, peripheral artery disorder coronary heart disease (CHD), stroke and various forms of cancer (Wang et al., 2006; States et al., 2009; Hughes et al., 2011; Mazumder \& Dasgupta, 2011). All these arsenic induced toxicity depend on many factors such as valence state, form (either organic or inorganic), particle size, solubility, rates of absorption and elimination (ATSDR, 2007). Epidemiologic evidences have demonstrated that ingestion of arsenic through drinking water might be responsible for the observed carcinogenic and non cancinogenic effects of arsenic (States et al., 2009; Mazumder \& Dasgupta, 2011; Roman et al., 2011). In acute lethality studies, trivalent arsenic (arsenite) was considered to be more toxic than pentavalent (arsenate) form (Albernathy et al., 1999; $\mathrm{Ng}, 2005$ ). In terms of forms, inorganic arsenic was regarded as more toxic than organic species. However, animal studies have shown that methyl arsenicals - monomethylarsonic acid (MMA) and dimethylarsinic acid (DMA) could produce adverse health effects similar to those produced by inorganic arsenic, especially with respect to chronic exposure (ATSDR, 2007; Albernathy et al., 1999).

Despite volumes of scientific findings about the toxic effects of arsenic, the time - course and possible mechanisms involved in arsenic - induced toxicity following acute and chronic arsenic exposure, as well as the threshold for biologic effects and disease risks remain enigmatic(Hughes et al., 2011). The present study however focused on the time - course of arsenic-induced hepatotoxicity and nephrotoxicity.

\section{Materials and Methods}

\subsection{Chemicals}

All chemicals used in this study were of the purest grade available and were obtained from the British Drug House (BDH) Chemicals Limited, Poole, England and Sigma-Aldrich, Missouri, U. S. A.

\subsection{Animals and treatment}

Sixty five (65) male albino rats weighing between 120 - $140 \mathrm{~g}$ were purchased from the animal house, Department of Physiology, Ladoke Akintola University of Technology, Ogbomoso, Oyo State, Nigeria. The animals were experimentally naïve, normal, and with no visible sign of diseases or injury. They were checked fully for rodent's infectious diseases visually. The animals were caged in the animal house and allowed to acclimatize for 14 days before the commencement of arsenic exposure. They were allowed free access to standard rat pellet diet purchased from Vita Feeds Nigeria Limited and drinking water ad libitum. Animals were maintained at temperature of $22 \pm 2^{\circ} \mathrm{C}$ and regular light-dark cycle (06:00-18:00h) throughout the study.

Five (5) animals served as baseline and were sacrificed at the commencement of the study to obtain the baseline data. The remaining sixty (60) animals were randomly divided into twelve (12) groups of five (5) animals each. Nine (9) groups were exposed to $100 \mathrm{ppm}, 150 \mathrm{ppm}$ and $200 \mathrm{ppm}$ inorganic arsenic as disodium arsenate (Na2HAsO4) in their drinking water each for four (4), eight (8) and twelve (12) weeks. The remaining three (3) groups served as control rats for each of the time intervals and received distilled water over the same period of time.

At the end of arsenic exposure blood was collected from the animals into heparinised tubes by cardiac puncture under light ether anesthesia after an overnight fast. The blood samples were centrifuged at $5000 \mathrm{rpm}$ for $10 \mathrm{~min}$ to obtain plasma and then stored at $-20 \circ \mathrm{C}$ until analysed. Liver was excised rinsed with normal saline and then divided into two portions. One portion was homogenized with phosphate buffer and the homogenate was kept at $20^{\circ} \mathrm{C}$ until used. The second portion was kept in $10 \%$ formalin for histological analysis.

\subsection{Biochemical Assay}

Alanine aminotransferase (ALT) and aspartate aminotransferase (AST) activities were assayed in the plasma by using the Labkit ${ }^{\circledR}$ reagent kits according to the method of Reitman and Frankel (Reitman and Frankel, 1957).Plasma $\gamma \mathrm{GT}$ was also assayed using Labkit® reagent kits following the standard method of Szasz (Szasz, 1969). ALP activity was assayed by the optimized standard method as recommended by Deutsche Gesellschaft fur Klinische Chemie (1972). Creatinine concentration was determined as described by Bartel et al. (Bartel et al., 1972). Urea concentration was also determined by Urease-Berthelot method.

\subsection{Histopathology}

Harvested livers were rinsed in phosphate buffered saline, blotted dry on filter paper and weighed. Sections of the liver were fixed in $10 \%$ p-formaldehyde processed and embedded in paraffin. The formalin fixed, paraffin embedded tissue was further sectioned and layered onto glass slide which was stained with haematoxylin-eosin dye and finally examined under light microscope as previously described by Hochegger et al., (2005). 


\subsection{Statistical evaluation}

Results were expressed as mean \pm SEM. One-way analysis of variance (ANOVA) followed by Tukey's test was used to analyze the results with $\mathrm{p}<0.05$ considered significant.

\section{Results}

Table 1: Body, liver weight and relative weight change in rat exposed to inorganic arsenic for 4 weeks.

\begin{tabular}{lllllll}
\hline & $\begin{array}{l}\text { Initial body } \\
\text { weight }(\mathrm{g})\end{array}$ & $\begin{array}{l}\text { Final Body } \\
\text { Weight }(\mathrm{g})\end{array}$ & $\begin{array}{l}\% \\
\text { change }\end{array}$ & Weight & Liver weight (g) & $\begin{array}{l}\text { Relative } \\
\text { weight }\end{array}$ \\
\hline Control & $146.8 \pm 7.53$ & $181 \pm 1.36 \mathrm{a}$ & 23.30 & $5.6 \pm 1.01 \mathrm{a}$ & $3.09 \pm 0.53 \mathrm{a}$ \\
$100 \mathrm{ppm}$ & $149.9 \pm 6.92$ & $124 \pm 3.73 \mathrm{~b}$ & 17.00 & $5.93 \pm 1.38 \mathrm{a}$ & $4.78 \pm 0.81 \mathrm{~b}$ \\
$150 \mathrm{ppm}$ & $150 \pm 4.89$ & $113.60 \pm 4.49 \mathrm{c}$ & 24.27 & $8.53 \pm 0.64 \mathrm{~b}$ & $7.51 \pm 1.10 \mathrm{c}$ \\
$200 \mathrm{ppm}$ & $148.4 \pm 9.57$ & $112.2 \pm 7.78 \mathrm{~d}$ & 24.39 & $7.7 \pm 0.99 \mathrm{a}$ & $6.86 \pm 0.37 \mathrm{~d}$ \\
\hline
\end{tabular}

Table 2: Body, liver weight and relative weight change in rat exposed to inorganic arsenic for 8 weeks.

\begin{tabular}{lllllll}
\hline & $\begin{array}{l}\text { Initial body } \\
\text { weight }(\mathrm{g})\end{array}$ & $\begin{array}{l}\text { Final Body } \\
\text { Weight }(\mathrm{g})\end{array}$ & $\begin{array}{l}\% \\
\text { change }\end{array}$ & Weight & Liver weight $(\mathrm{g})$ & $\begin{array}{l}\text { Relative } \\
\text { weight }\end{array}$ \\
\hline Control & $148.8 \pm 7.58$ & $193.1 \pm 1.05 \mathrm{a}$ & 29.77 & $5.91 \pm 1.21 \mathrm{a}$ & $3.06 \pm 0.76 \mathrm{a}$ \\
$100 \mathrm{ppm}$ & $147.9 \pm 2.56$ & $134.2 \pm 1.46 \mathrm{~b}$ & 9.26 & $6.09 \pm 1.11 \mathrm{a}$ & $4.54 \pm 0.41 \mathrm{~b}$ \\
$150 \mathrm{ppm}$ & $137 \pm 8.06$ & $121 \pm 4.31 \mathrm{c}$ & 11.68 & $6.91 \pm 0.88 \mathrm{a}$ & $5.71 \pm 0.72 \mathrm{c}$ \\
$200 \mathrm{ppm}$ & $145.2 \pm 7.25$ & $119 \pm 3.53 \mathrm{~d}$ & 18.04 & $6.61 \pm 0.53 \mathrm{a}$ & $5.55 \pm 0.43 \mathrm{~d}$ \\
\hline
\end{tabular}

Table 3: Body, liver weight and relative weight change in rat exposed to inorganic arsenic for 12 weeks.

\begin{tabular}{lllllll}
\hline & $\begin{array}{l}\text { Initial body } \\
\text { weight }(\mathrm{g})\end{array}$ & $\begin{array}{l}\text { Final Body } \\
\text { Weight }(\mathrm{g})\end{array}$ & $\begin{array}{l}\% \\
\text { change }\end{array}$ & Weight & Liver weight $(\mathrm{g})$ & $\begin{array}{l}\text { Relative } \\
\text { weight }\end{array}$ \\
\hline Control & $135.50 \pm 8.06$ & $178.80 \pm 1.05 \mathrm{a}$ & 31.96 & $6.55 \pm 1.49 \mathrm{a}$ & $3.66 \pm 0.80 \mathrm{a}$ \\
$100 \mathrm{ppm}$ & $148.00 \pm 8.18$ & $108.70 \pm 4.07 \mathrm{~b}$ & 25.55 & $7.14 \pm 1.08 \mathrm{a}$ & $6.57 \pm 0.71 \mathrm{~b}$ \\
$150 \mathrm{ppm}$ & $146.00 \pm 3.14$ & $101.4 \pm 6.48 \mathrm{c}$ & 30.55 & $8.52 \pm 0.78 \mathrm{~b}$ & $8.40 \pm 0.32 \mathrm{c}$ \\
$200 \mathrm{ppm}$ & $147.00 \pm 7.58$ & $97.00 \pm 3.79 \mathrm{~d}$ & 34.01 & $8.20 \pm 0.91 \mathrm{c}$ & $8.45 \pm 0.91 \mathrm{~d}$ \\
\hline
\end{tabular}

Tables 1, 2 and 3 summarizes the initial, terminal body weights, percentage weight change, liver weight and relative liver weight of the animals exposed to 100, 150 and $200 \mathrm{ppm}$ inorganic arsenical for 4,8 and 12 weeks respectively. Body weight of the animals in the control groups increased progressively by $23.30,29.77$ and $31.96 \%$ respectively for 4, 8 and 12 weeks. Arsenic exposure led to a continuous reduction in body weight that is significant at all time interval and doses. As illustrated, in each time interval, the reduction in body weight increased with increasing doses of the arsenical. The most dramatic reduction in body weight of the magnitude $25.55,30.55$ and $34.01 \%$ was elicited by 100,150 and $300 \mathrm{ppm}$ arsenic respectively after twelve weeks of exposure. Correspondingly, when compared with the control group, there was a significant increase in relative liver weight of the animals exposed to the arsenical. This observed increase in relative liver weight was dose - dependent at both 8 and 12 weeks of exposure. 


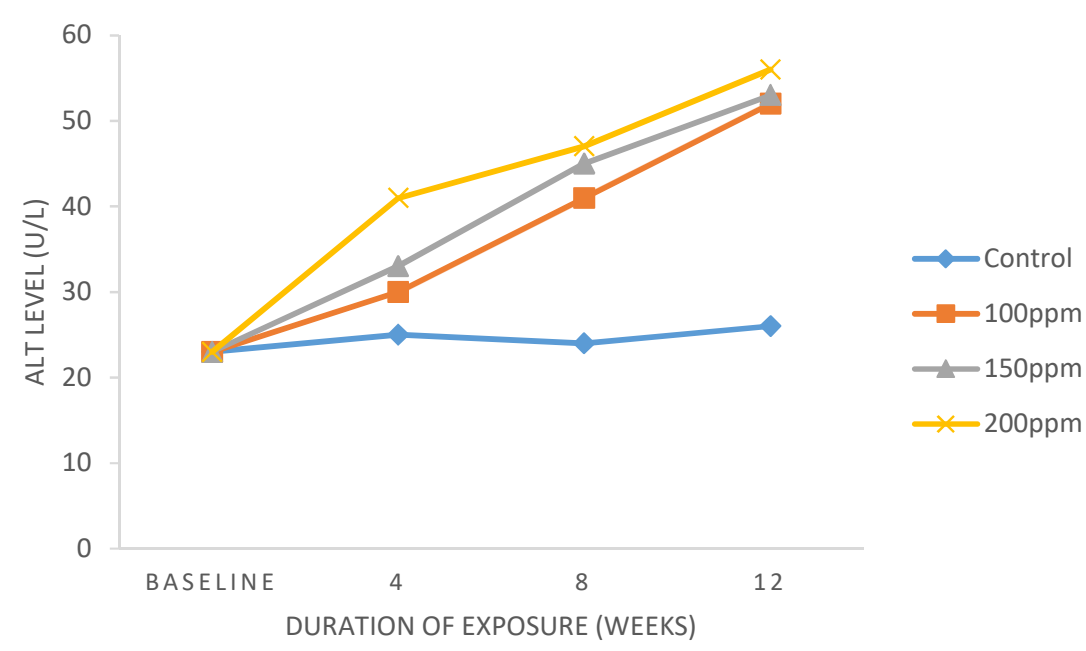

Fig. 1: Plasma ALT level in rats exposed to different doses of inorganic arsenic.

As shown in fig. 1, exposure of animals to low (100 ppm), intermediate (150 ppm) and high (200 ppm) doses of inorganic arsenate led to a time and dose dependent increase $(p<0.05)$ in plasma level of AST. At 4 weeks. The three doses of 100, 150 and $200 \mathrm{ppm}$ arsenic produced $20 \%, 30 \%$ and $64 \%$ increase respectively. Following the extension of the duration of the same doses of arsenic to 8 weeks the magnitude on the increment became $70 \%$, $87 \%$ and $95 \%$ respectively. Meanwhile, at 12 weeks the three doses of the arsenic compound increased the level of ALT in circulation to nearly $100 \%$

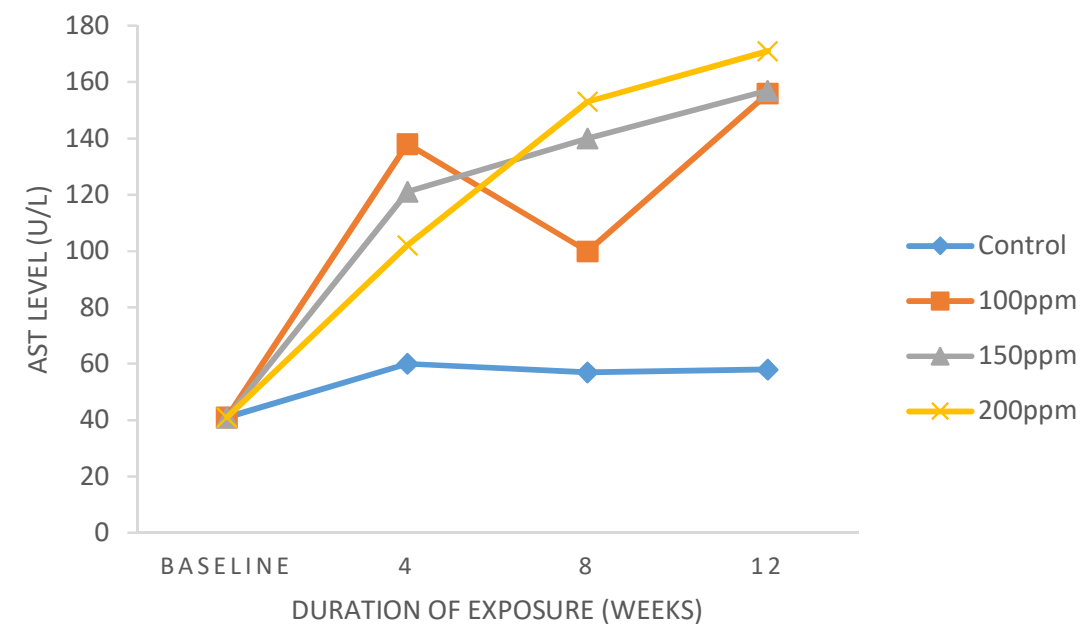

Fig.2: Plasma AST level in rats exposed to different doses of inorganic arsenic.

As presented in fig. 2, exposure of animals to 100,150 and $200 \mathrm{ppm}$ inorganic arsenic for 4, 8 and 12 weeks increased the level of AST in circulation at all doses and duration of exposure. As illustrated in the figure the effects of 150 and $200 \mathrm{ppm}$ arsenic was time dependent. At weeks, the three doses of the arsenic elicited a hormetic response in plasma AST levels. On the other hand, when the duration of exposure was increased to 8 and 12 weeks, the response to arsenic exposure was dose dependent. The maximal response to arsenic exposure was observed at 12 weeks. Exposure to 100 and 200 ppm arsenate produced about 2.5 - fold increase in plasma AST level, while 200 ppm caused about 3 - fold increase. 


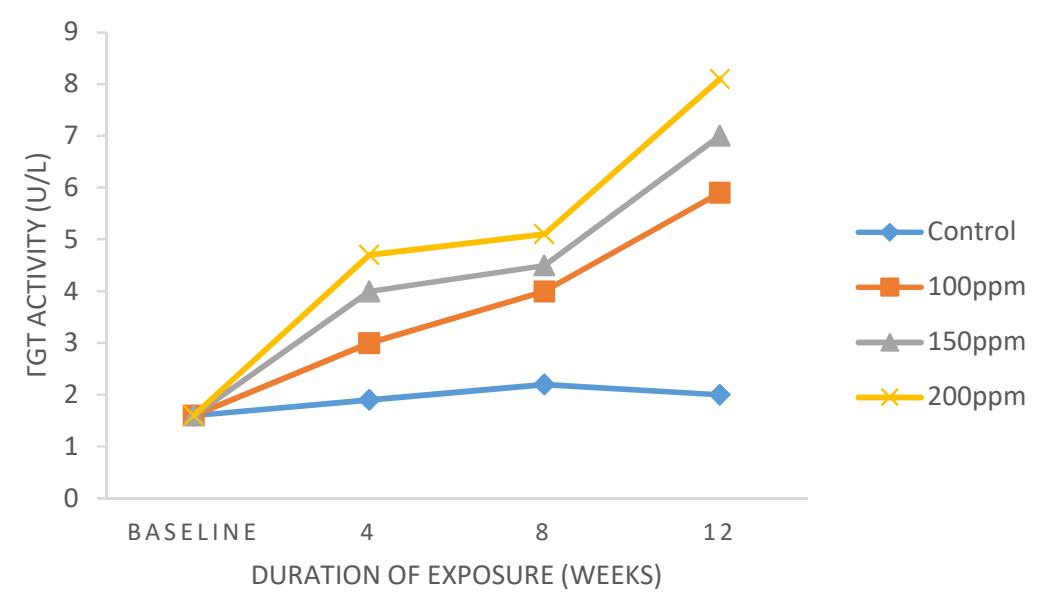

Fig.3: Plasma $\gamma$ GT level in rats exposed to different doses of inorganic arsenic.

As depicted in fig. 3, exposure to 100, 150 and $200 \mathrm{ppm}$ sodium arsenate for 4, 8 and 12 weeks induced a significant dose - and time - dependent increase in the activity of $\gamma \mathrm{GT}$ in circulation. For instance, the minimal $(2-$ fold increase in plasma activity) and maximal ( 4 - fold increase in plasma activity) effects were elicited by exposure to $100 \mathrm{ppm}$ for 4 weeks and $200 \mathrm{ppm}$ for 12 weeks respectively.

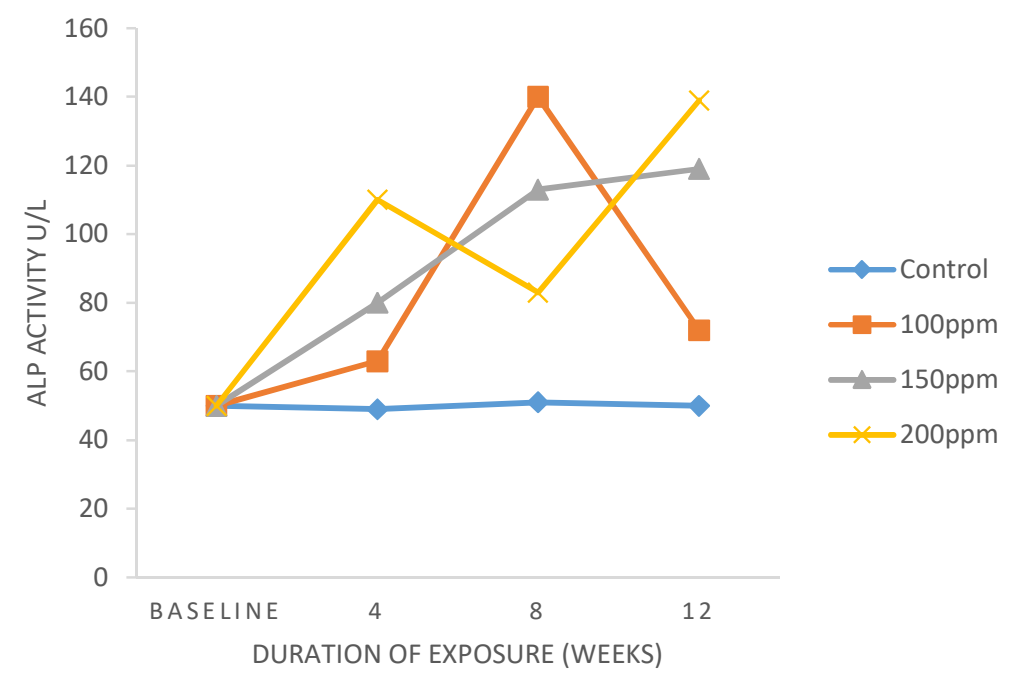

Fig.4: Plasma ALP level in rats exposed to different doses of inorganic arsenic.

Exposure of the animals to the arsenical increased the plasma level of ALP significantly (fig. 4). The observed effect was dose dependent at both 4 and 12 weeks of exposure. On the other hand, after 8 weeks of exposure, the lowest dose of $100 \mathrm{ppm}$ sodium arsenate caused the maximal effect on the plasma level of ALP, while the lowest effect was induced by the highest dose of $200 \mathrm{ppm}$. 


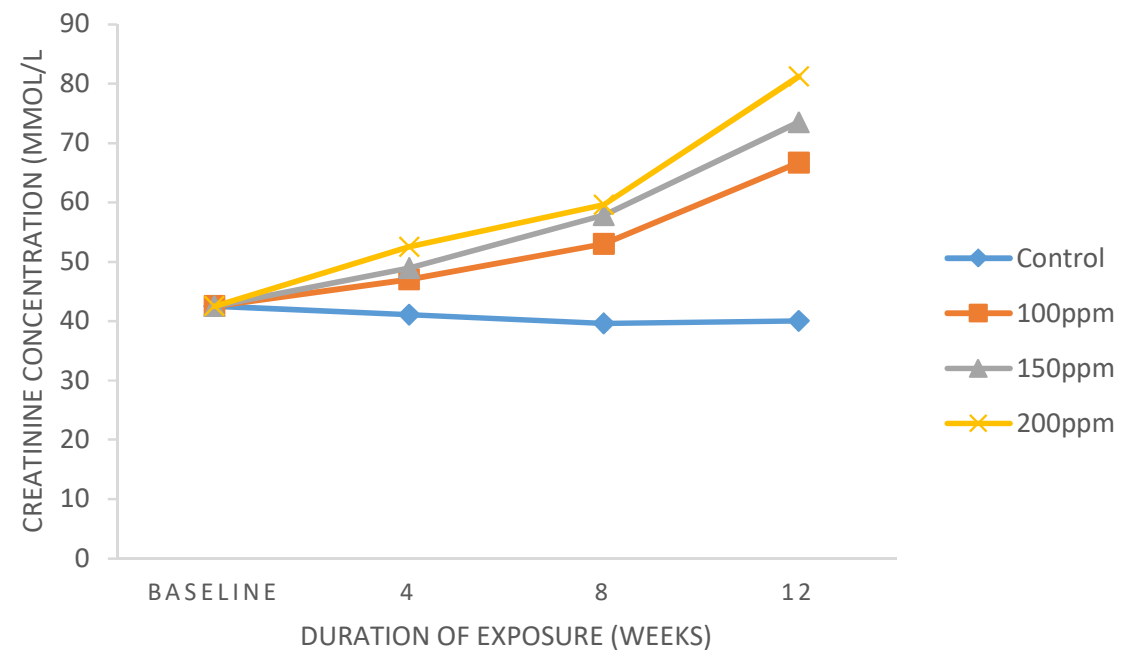

Fig.5: Plasma Creatinine Concentration in rats exposed to different doses of inorganic arsenic.

As depicted in fig 5, exposure to the three doses of the arsenicals up - regulated plasma creatinine level significantly. This increment in plasma creatinine concentration was dose - and time - dependent. For instance, the magnitude of the effect of exposure to $100 \mathrm{ppm}$ inorganic arsenic for 4 weeks was $14 \%$ increase in plasma creatinine concentration. When the dose and duration of exposure was increased to $200 \mathrm{ppm}$ and 12 weeks respectively, the magnitude the effects was increased to $100 \%$.

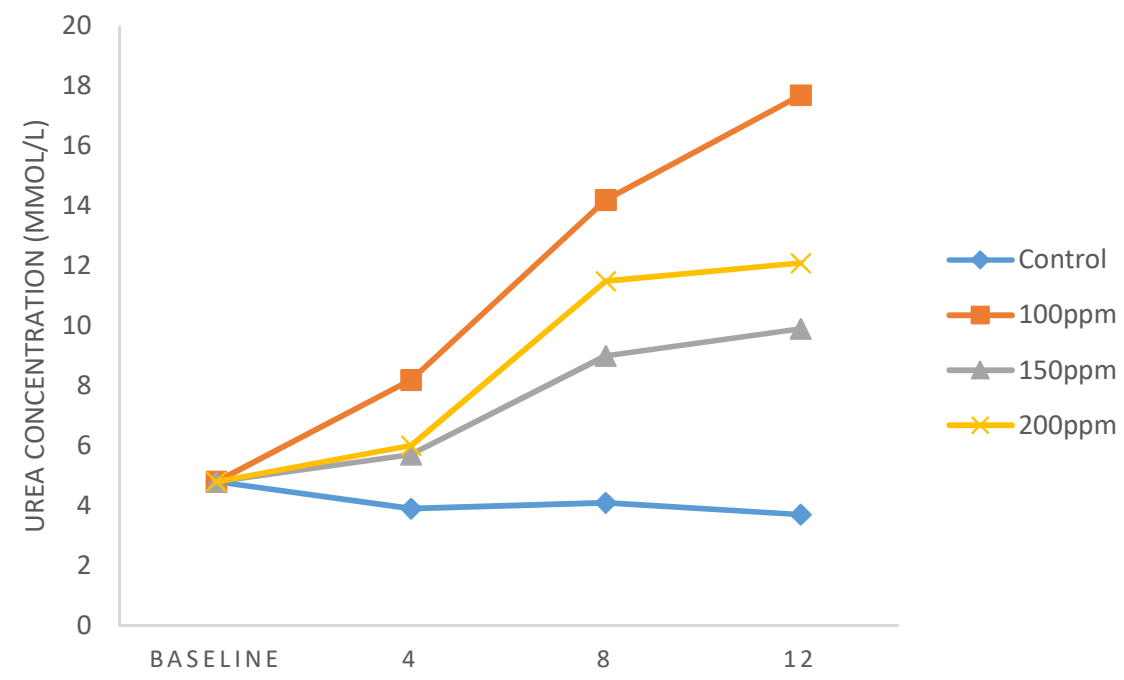

Fig.6: Plasma Urea Concentration in rats exposed to different doses of inorganic arsenic.

The mean plasma urea concentrations of the animals is illustrated in fig. 6. Treated of the animals with doses of inorganic arsenic for 4, 8 and 12 weeks caused a significant increase in the concentration of urea in the plasma. Interestingly, the lowest dose of $100 \mathrm{ppm}$ caused the most significant up - regulation of the plasma urea content. For instance, the dose regimen caused about 2, 3 and 5 folds increase in plasma urea concentration at 4, 8 and 12 weeks of exposure respectively. The increment caused by the different dose regimens was sustained in a time dependent fashion. 


\section{Fig. 7: Histologic Examination.}

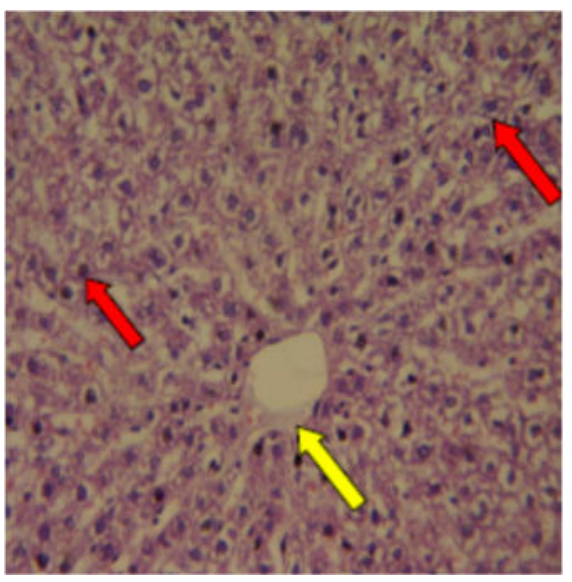

A: Baseline: showing normal cytoarchitectcture of the hepatocytes (yellow arrow) and reticular fibres (yellow arrow) in the wall of central vein and sinusoids. The cells are centrally located with some some kupfer cells seen (X40)

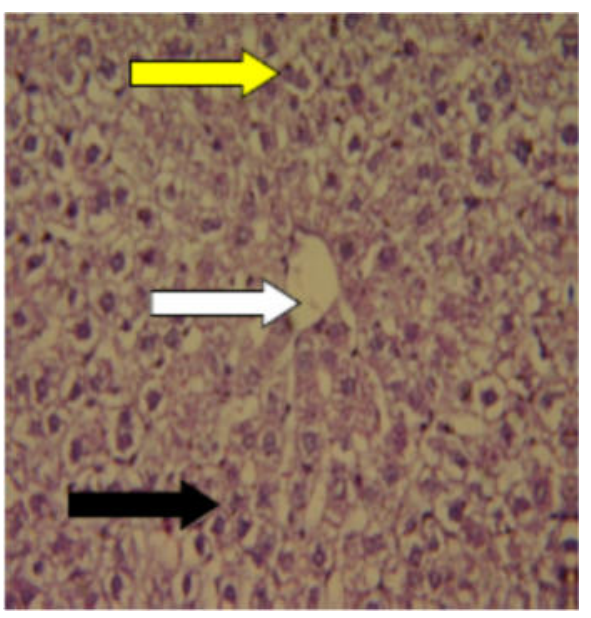

B: Control (4 weeks): showing normal cytoarchitectcture of the hepatocytes and reticular fibres (black arrow) in the wall of central vein and sinusoids. The nucleus are centrally located with some element of binucleation (yellow arrow) as a sign of normal cell division (X40).

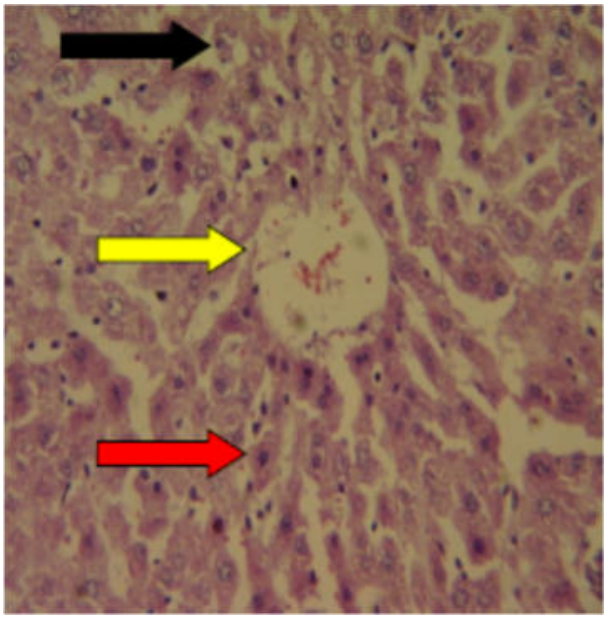

C: 100ppm of inorganic arsenate (4weeks): Showing distorted cytoarchitectecture with necrotic cells (black arrow), degenerated reticular fibres of the central vein (yellow arrow) and enlarged sinusoids (red arrow) (X40). 


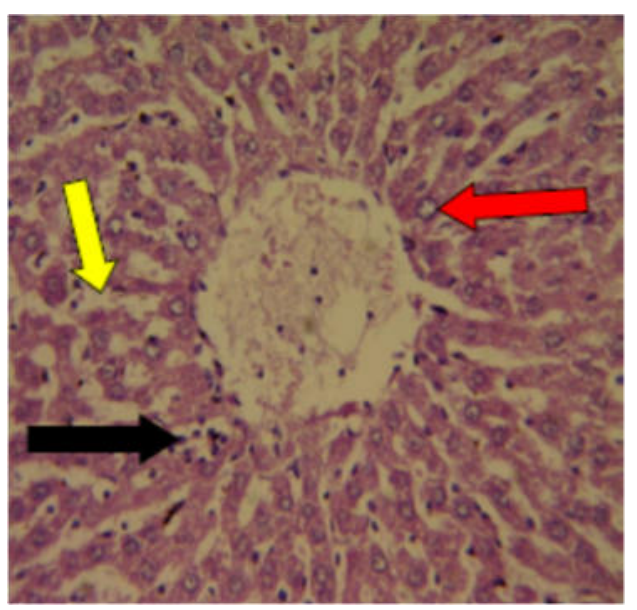

D: 150ppm of inorganic arsenate (4 weeks): Showing cells with degenerated cytoplasmic content (black arrow), anucleolus (red arrow) and necrotic cells (yellow arrow) (X40).

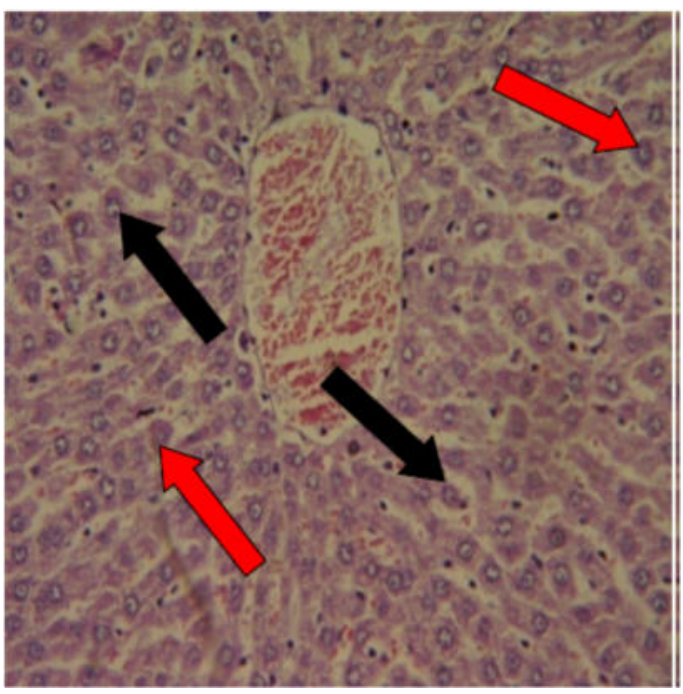

E: 200ppm of inorganic arsenate (4 weeks): Showing normal hepatic cytoarchitectecture with necrotic cells (black arrow), and few cytoplasmic inclusion (red arrow) (X40).

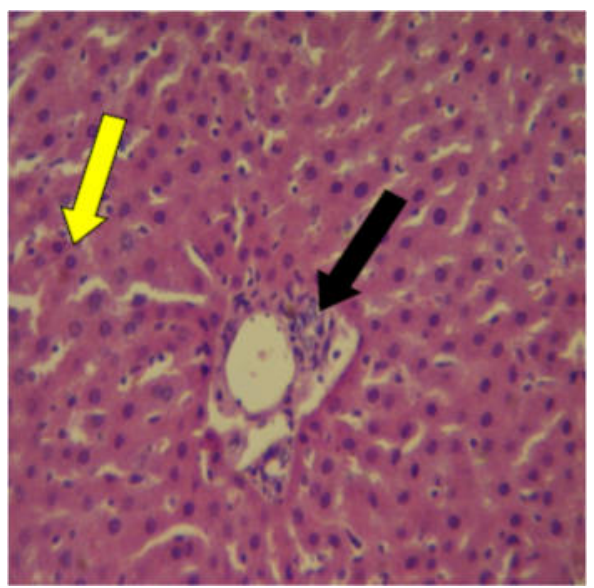

F: Control (8 weeks): showing normal cytoarchitectcture of the hepatocytes and reticular fibres (black arrow) in the wall of central vein and sinusoids. The nucleus are centrally located with some element of binucleation (yellow arrow) as a sign of normal cell division (X40). 


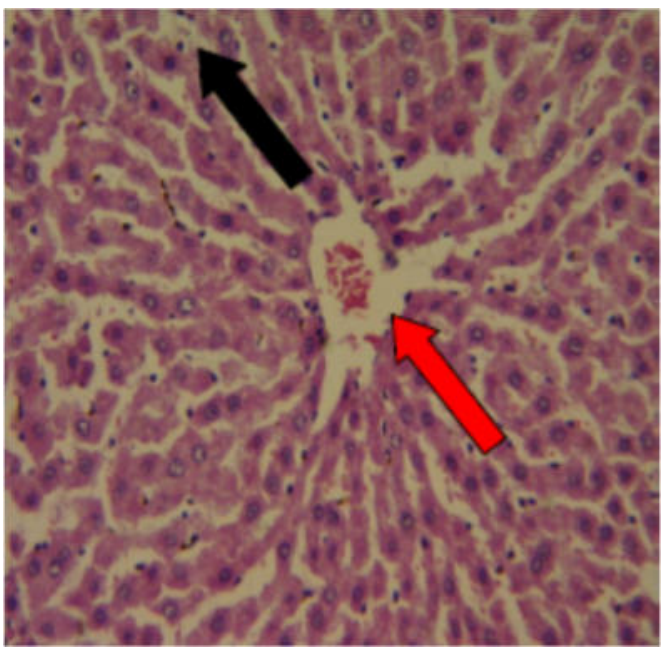

G: 100ppm of inorganic arsenate (8 weeks): Showing distorted cytoarchitectecture with necrotic cells (black arrow) and a collapsed central vein (red arrow) (X40).

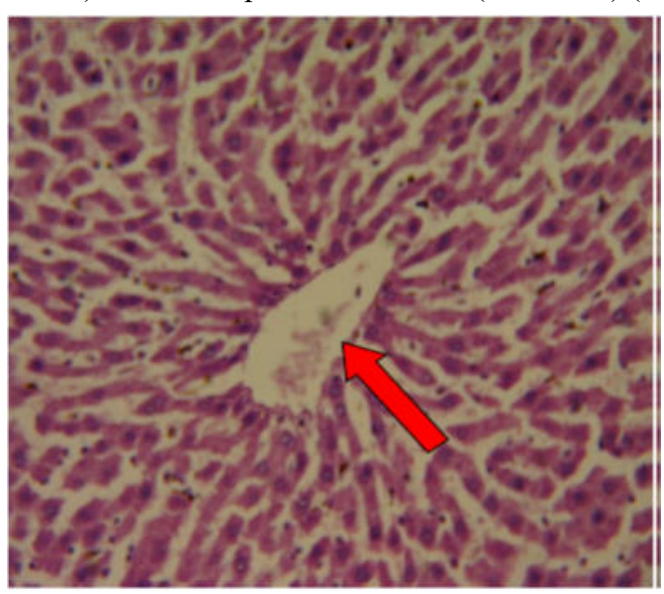

H: 150ppm of inorganic arsenate (8 weeks): Showing cells a normal central vein with distorted cytoarchitecture mainly caused by cytoplasmic inclusion (X40). 


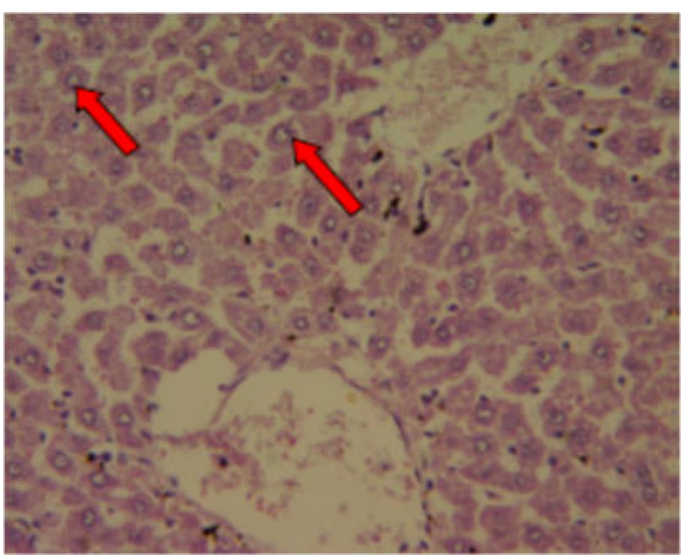

I: 200ppm of inorganic arsenate (8 weeks): Showing enlarged hepatic sinusoids, undifferentiated cytoarchitectecture and hydropic degeneration of the hepatocytes (red arrow) (X40).

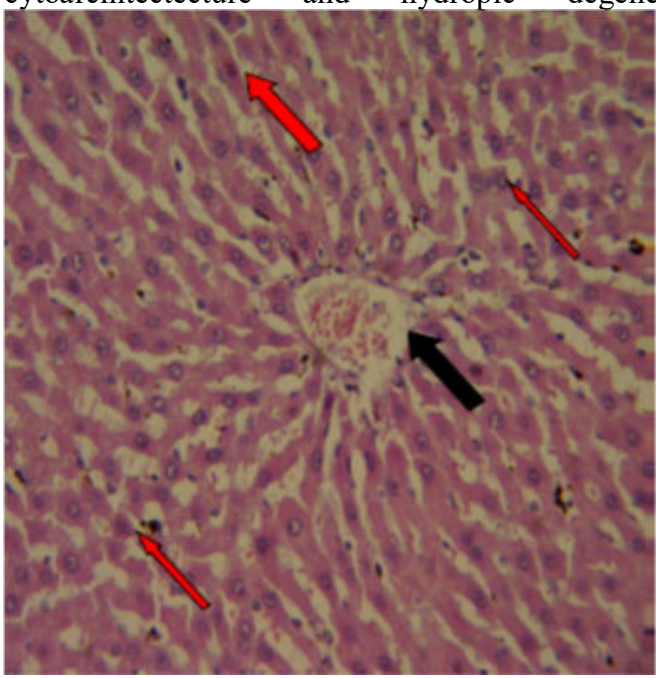

J: Control (12 weeks): showing normal cytoarchitectcture of the hepatocytes and reticular fibres (black arrow) in the wall of portal vein and sinusoids. The cells are centrally located with some demonstration of cytoplasmic eosinophilic (red arrow) (X40).

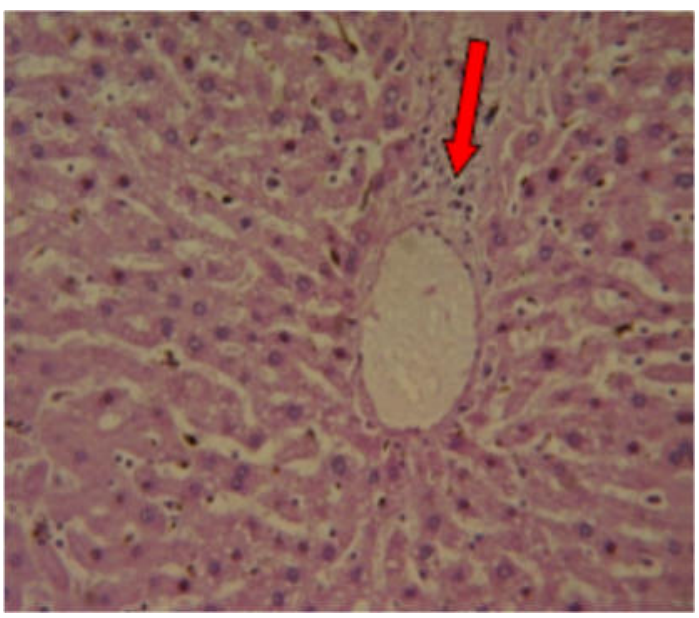

K: 100ppm of inorganic arsenate - 12 weeks: Showing some aggregate of inflammatory cells at the central vein (red arrow) (X40). 


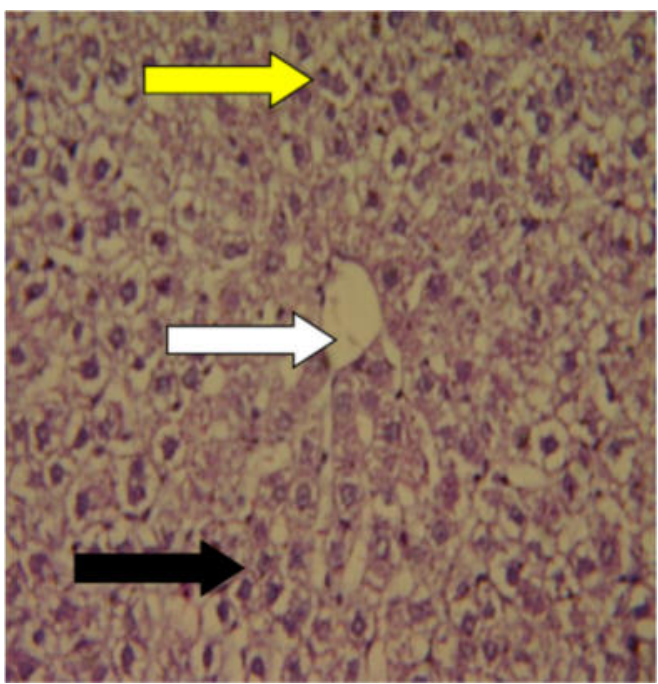

L: $150 \mathrm{ppm}$ of inorganic arsenate (12 weeks): Demonstrating showing hepatocytes with high cytoplasmic inclusions (red arrow) and some aggregate of inflammatory cells at the central vein (yellow arrow). The central vein appears normal (white arrow).

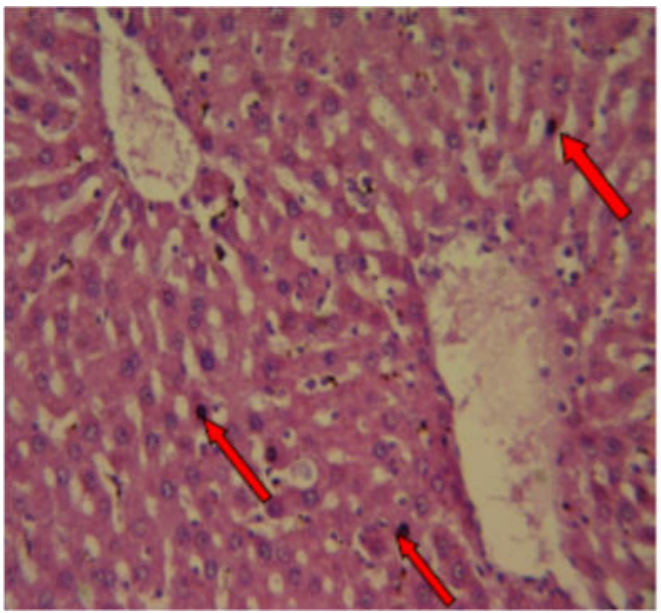

M: 200ppm of inorganic arsenate (12 weeks): Demonstrating kupfer cell hyperplasia (red arrow) (X40).

\section{Discussion}

The results from the present study demonstrated that exposure of rats to pentavalent inorganic arsenic through the drinking water could be associated with hepatic and renal toxicities. Compared with the control animals, the arsenical caused a general and significant decline in the average weight of the animals, increased relative liver weight, perturbed levels of ALT, AST, $\gamma \mathrm{GT}$, ALP, creatinine and urea in circulation. These perturbations was characterized by a significant elevation in their respective concentration in the plasma.

Exposure of animals to inorganic arsenic through their drinking water resulted into substantial loss in body weight compared with the control animals which shows a progressive increase in body weight, as such the arsenical even at dose as low as $100 \mathrm{ppm}$ and as early as 4 weeks of exposure appears to have a huge overall systemic effect on the animals. Corroboratively, steady increase in relative liver weight was also observed in the groups that were exposed to the arsenic compound. The increase in relative liver weight may be as a result of increased number of hepatocytes caused by arsenic - induced unregulated hepatocyte proliferation. This finding is in agreement with the previous research by Owumi et al. (2015). In their study, they recorded the highest number of cells $/ \mathrm{mm} 2 \mathrm{in}$ groups with highest mean relative liver weight

Hepatocytes are the major target for chemically induced injuries and this may be due to the very vital role of liver in the metabolism and detoxification of toxic chemical agents. There are high activities of xenobiotic metabolizing 
enzymes in the liver, especially the cytochrome P450 - dependent monooxygenase system. The oxidative biotransformation by this enzyme produces many reactive metabolites that can induce plethora of damage effects on the hepatocytes (Jing \& Teschke, 2018). Assessment of plasma level of liver transaminases, such as ALT, AST and $\mu \mathrm{GT}$ has been found to be greatly important in the clinical and environmental investigation of liver injury. The raised levels of these enzymes in circulation are sensitive traditional marker of hepatic injury. These enzymes are synthesized in the hepatocytes and function in the metabolism of amino acids (Owumi et al., 2015), and are therefore used in determining occurrence of hepatocellular diseases. Our findings in the present study reveal that exposure of animals to inorganic arsenic for 4, 8 and 12 weeks significantly elevated the levels of ALT, AST and $\mu \mathrm{GT}$ in circulation (Figs 1, 2 and 3) relative to controls. This is an indication of arsenic - induced compromise of the hepatocytes structural integrity. This finding suggests that inorganic arsenate exposure at low, intermediate and high doses for 4, 8 and 12 weeks can damage hepatocytes and cause leakages of hepatic transaminases into the blood.

ALP is a non - specific phosphoric monoesterase and a dimeric metalloenzyme containing $\mathrm{Zn} 2+$ and $\mathrm{Mg} 2+$ ions coordinated to its active site (Shyuan et al., 2008). It is a ubiquitous intracellular enzyme that catalyzes the hydrolysis of organic phosphoesters but as noted by Newsome et al. (2018), it is produced mainly in the liver. High plasma ALP activity has been found in patients with liver cancer (Bhudhisawasdi, et al., 2004). The present study noted elevated activities of ALP in the plasma of arsenic - exposed groups compared with the control (Fig 4). This study had earlier observed increased relative liver weight in the arsenic group which at this point could be correlated with the observed elevated ALP activity and suggest that the elevated plasma ALP activity was as a result of arsenic - induced unregulated hepatocytes proliferation; a major feature of cancerous cells.

Creatine is a dietary non - essential amino acid that is phosphorylated in the hepatocytes, kidney and pancreas by creatine kinase. The phosphorylated creatine is then subsequently released into circulation and stored by organs such as the muscle and brain for growth, tissue repair, and energy dependent activities (Newman and price, 2001; Bhagavan, 2002; Watras, 2008). In muscle however, creatine dephosphorylation releases energy needed for muscle contraction. About $2 \%$ of muscle free creatine are irreversibly and spontaneously converted to creatinine which in turn is released into circulation and freely filtered and excreted by the kidneys (Curhan and Mitch, 2008). Creatinine therefore is a by - product of normal muscle function. Its level in the blood is therefore a reflection of kidney function, and its elevated level in circulation is an indication of inefficient filtration by the kidney. Urea is the principal nitrogenous waste product of protein metabolism and just like creatinine, it is eliminated from the body almost exclusively by the kidneys in the urine. Plasma urea concentration therefore is also a reflection of the balance between hepatic urea production and renal urea elimination. Meanwhile, the highest levels of circulatory urea occur in the context of decreased urinary elimination of urea due to advanced renal diseases and associated marked reduction in glomerular filtration rate (GFR). This study however noticed elevated levels in both creatinine and urea in the arsenic - treated rats relative to the control groups. The elevated plasma creatinine and urea in the rats suggests that arsenic may potentially cause renal impairment due to tubular damage or reduced glomerular filtration (Vasudevan \& Sreekumari, 2005). This finding therefore suggests the nephrotoxic potential of inorganic arsenic.

Histopathological assessment of the experimental rats exposed to various dose regimens of inorganic arsenic for the three time interval was also carried out. There were disruption of normal cytoarchitecture, degeneration of cytoplasmic contents, evidence of necrosis, collapse of central vein, cytoplasmic inclusion, enlarged hepatic sinusoids with undifferentiated cytoarchitecture with hydropic degeneration of the hepatocytes and aggregate of inflammatory cells noticed at the central vein and kupfer cell hyperplasia in the arsenic - treated rats. Contrarily, the hepatic tissues of the baseline and control rats showed a normal feature with hepatocytes having central nucleus and some element of binucleation, a sign of normal cell division.

\section{Conclusion}

Taken together, it can be concluded from the findings of the present study that the hepatotoxicity and nephrotoxicity potential of inorganic arsenate is time dependent. Furthermore, it should also be emphasized that even at a very low dose and very few weeks of exposure, the arsenical is capable of compromising the integrity and efficiency of these vital organs. 


\section{References}

Albernathy, C. O., Liu, Y., Longfellow, D., Aposhian, H.V., Beck, B., Fowler, B., Goyer, R., Menzer, R., Rossman, T., Thompson, C. \&Waalkes, M. (1999), “Arsenic: Health Effects, Mechanisms of Actions, and Research Issues", Environmental Health Perspectives 107, 593-597.

ATSDR. (2007), “Toxicological Profile for Arsenic.” Agency for Toxic Substances and Disease Registry, U.S. Department of Health and Human Services, Atlanta, GA. Available at: http://www.atsdr.cdc.gov/ToxProfiles/tp2.pdf.

Bartels, H., Bohmer, M., \&Heierli, C. (1972), "Serum creatinine determination without protein precipitation”, Clin Chim Acta., 37, 193-197.

Bhagavan, N. V. (2002), "Protein and Amino Acid Metabolism," In: J. Hayhurst, Ed., Medical Biochemistry, Harcourt/ Academic Press, Burlington, pp. 331-332.

Bhudhisawasdi, V., Muisuk, K., Areejitranusorn, P., Kularbkaew, C., Khampitak, T., Saeseow, O. \&Wongkham, S. (2004), "Clinical value of biliary alkaline phosphatase in non-jaundiced cholangiocarcinoma", J. Cancer Res Clin Oncol, 130, 87-92.

Chowdhury, U. K., Biswas, B. K., Chodhury, T. R. \& Mukherjee, S. K. (2000), Groundwater arsenic contamination in Bangladesh and West Bengal, India, Environ Health Perspect., 108, 393-397.

Clarkson, T. (1995), “Health Effects of Metals: A Role for Evolution?”,Environ. Health Perspect, 103, 9-12.

Curhan, G. C. \& Mitch, W. E. (2008), "Brenner \& Rector's The Kidney,” 8th Edition. Saunders, Philadelphia, pp. 1826-1827.

Deutsche Gesellschaft fur KlinischeChemie., J Clin Chem Clin Biochem. 1972; 10, 182.

Gbadegesin, M. A., Odunola, O. A., Akinwumi, K. A. \&Osifeso, O. O. (2009), “Comparative hepatotoxicity and clastogenicity of sodium arsenite and three petroleum products in experimental Swiss Albino Mice: the modulatory effects of Aloe vera gel". Food ChemToxicol 47(10), 2454-2457.

Goering, P. L., Aposhian, H. V., Mass, M. J., Cebrian, M., Beck, B. D. \&Waalkes, M. P. (1999) “The enigma of arsenic carcinogenesis: role of metabolism" Toxicol. Sci.49, 5-14.

Guillamet, E., Creus, A., Ponti, J., Sabbioni, E., Fortaner, S. \& Marcos, R. (2004), "In vitro DNA damage by arsenic compounds in a human lymphoblastoid cell line (TK6) assessed by the alkaline Comet assay", Mutagenesis 19(2), 129-135.

Haider, S. S. \&Najar, M. S. A. (2008), “Arsenic induces oxidative stress, sphingolipidosis, depletes proteins and some antioxidants in various regions of rat brain", Kathmandu University Medical Journal 6 (21), 60-69.

Hochegger, K. F., Siebenhaar, V., Vielhauer, D., Heininger, T. N., Mayadas, G., Mayer, M. \&Rosenkranz, A. R. (2005), "Role of mast cells in ex $\neg$ perimental anti-glomerular basement membrane glomerulonephritis", Eur $J$ Immunol 35, 3074-3082.

Hu, H. (2000), “Exposure to metals”, Prim. Care 2, 983-996

Hughes, M. F., Beck, B. D., Chen, Y., Lewis, A. S. \& Thomas, D. J. (2011), “Arsenic exposure and toxicology: a historical perspective", Toxicological Sciences 123(2), 305-332.

Jing, J \& Teschke, R. (2018), “Traditional Chinese Medicine and herb-induced Liver Injury: comparison with Druginduced liver Injury”, J Clin transl Hepatol 28;6(1), 57-68.

Mazumder, D. G. \&Dasgupta, U. B. (2011), "Chronic arsenic toxicity: studies in West Bengal, India. Kaohsiung." Journal of Medicine and Medical Sciences 27, 360-370.

Newman, D. J. \& Price, C. P (2001), "Nonprotein Nitrogen Me- tabolites,” In: C. A. Burtis and E. Ashwood, R. Eds., Ti- etz Fundamentals of Clinical Chemistry, W.B. Saunders Company, Philadelphia, pp. 414-422.

Newsome, P. N., Cramb, R., Davison, S. M., Dillon, J. F., Foulerton, M., Godfrey, E. M.,Hall, R., Harrower, U., Hudson, M., Langford, A., Mackie, A., Mitchell-Thain, R., Sennett, K., Sheron, N. C., Verne, J., Walmsley, M. \& Yeoman, A. (2018), "Guidelines on the management of abnormal liver blood tests", Gut67, 6-19.

$\mathrm{Ng}$, J. C. (2005). "Environmental contamination of arsenic and its toxicological impact on humans”, 2, 146-160.

Odunola, O. A., Uka, E., Akinwumi, K. A., Gbadegesin, M. A., Osifeso, O. O. \&Ibegbu, M. D. (2008). Exposure of laboratory mice to domestic cooking gas: implications for toxicity. Int J Environ Res Public Health 5(3), 172176. 
Owumi, S. E., Fatoki, J. O., Gbadegesin, M. A. \&Odunola, O. A. (2015), "Clastogenic and toxicological assessment of cashew (Anacardiumoccidentale) nut extracts in Wistar rats". Acta Biochimica Polonica, 62(3/2015), 563-567.

Pradosh, R. \&Anupama, S. (2002), "Metabolism and Toxicity of Arsenic: A Human Carcinogen”, Current Science 82(1), 38-45.

Reitman, S. \& Frankel, S. (1957) "A colorimetric method for the determi $\neg$ nation of serum glutamic oxalacetic and glutamic pyruvic transami $\neg$ nases”, Am J Clin Pathol 28, 56-63.

Roman, D. A., Pizarro, I., Rivera, L., Camara, C., Palacios, M. A., Gomesz, M. M. \& Solar, C. (2011), “An approach to the arsenic status in cardiovascular tissues of patients with coronary heart disease", Hum Exp Toxicol 30(9), 1150-1164.

Rordriguez, V. M., Jimenez-Capdevillie, M. E. \& Giordano, M. (2003), "The Effect of arsenic exposure on the nervous system", Toxicol Letters 145, 1-18.

Shyuan, L. K., Heng, K. Y., Ahmad, M., Aziz, S. A. \& Ishak, Z. (2008), "Evaluation of pesticide and heavy metal toxicity using immobilized enzyme alkaline phosphatase with nan electrochemical biosensor" Asian Journal of Biochemistry, 3(6), 359-365.

Smeester, L., Rager, J. E., Bailey, K. A., Guan, X., Smith, N. \& Garcia-Vargas, G. (2011), “Epigenetic changes in individuals with arsenicosis", Chemical Resaerch in Toxicology 24, 165-167.

States, J. C., Srivastava, S., Chen, Y. \&Barchowsky, A. (2009), “Arsenic and cardiovascular disease.” Toxicological Sciences 107, 312-323.

Szasz, G. A (1969), "kinetic photometric method for serum $\gamma$-glutamyltranspeptidase", Clin Chem. 15, 124-136.

Vasudevan, D. M. \& Sreekumari, S. (2005), “Textbook of Biochemistry for Medical Students” 4th ed. New Delhi: JAYPEE Brothers Medical Publishers pp 249-257.

Wang, C., Hsiao, C. K., Chen, C., Hsu, L., Chiou, H., Chen, S., Hsueh, Y., Wu, M. \& Chen, C. (2006). “A review of the epidemiologic literature on the role of environmental arsenic exposure and cardiovascular diseases", Toxicology and Applied Pharmacology 222(2007), 315-326

Watras, J. M. (2008) “Berne \& Levy Physiology,” 6th Edition. Mosy, Inc., Santa Clara, pp. 246-247. 